\title{
Aplicação de modelos virtuais para comparação entre tratamentos ortodônticos para verticalização de segundo molar.
}

\section{Letícia De Mattei Gonçalves*, Pedro Noritomi.}

\section{Resumo}

Neste trabalho, busca-se apresentar, concisamente, o estudo de um caso recebido pelo laboratório de bioengenharia do Núcleo de Tecnologias Tridimensionais do CTI Renato Archer. Neste estudo, aplicaram-se conceitos de engenharia como o Método dos Elementos Finitos para o estudo sobre a distribuição de forças e deslocamentos nas estruturas ósseas e biológicas de uma mandíbula apresentando o segundo molar inclinado. A partir da representação biomecânica e modelagem anatômica, fez-se possível que um ortodontista avalie qual o melhor tratamento a ser usado em cada caso e quais as possíveis diferenças no resultado obtido pelo uso de diferentes aparelhos ortodônticos.

\section{Palavras-chave:}

Bioengenharia, Método de Elementos Finitos, Ortodontia.

\section{Introdução}

A bioengenharia é o ramo que permite a aplicação de conceitos relacionados comumente à engenharia na área da saúde. Apesar de se tratar de um campo de pesquisa associado aos avanços tecnológicos, é um conceito bastante antigo, sendo possível rastrear o uso de próteses de madeira e couro em múmias egípcias.

$\mathrm{Na}$ odontologia, a bioengenharia está presente nos avanços na área de simulação por elementos finitos de arcadas dentárias, possibilitando a simulação e avaliação da distribuição de tensões e deformações a partir de um determinado aparelho ortodôntico.

Objetivou-se, com o presente trabalho, gerar um modelo computacional compatível com a anatomia de uma mandíbula cujos segundos molares necessitem de tratamento para verticalização, bem como elaborar toda a etapa de discretização de tal modelo, para posterior processamento e análise de resultados da simulação.

\section{Resultados e Discussão}

O modelo final discretizado está exemplificado na figura 1. Com a discretização, obteve-se uma malha com 2.171.819 elementos e 506.106 nós.

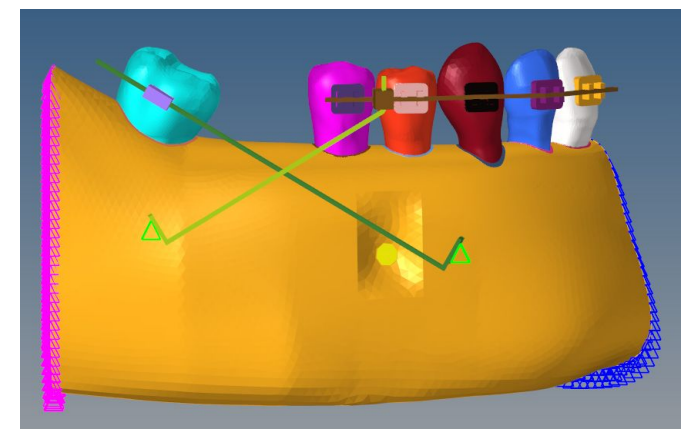

Figura 1. Modelo computacional gerado no software Rhinocerus 3D e discretização no Hypermesh 17.2
A malha final conta com diferentes tamanhos de elemento, de acordo com os arredores de cada componente. $\mathrm{Na}$ região da raiz do dente, por exemplo, há contato com o ligamento periodontal, logo há elementos menores. $\mathrm{Na}$ região da coroa, nota-se um região de refino, que fica em contato com o braquete. Fora dessa região, os elementos podem ser maiores sem prejudicar a qualidade da simulação.

Os triângulos em rosa representam a condição de contorno de fixação na extremidade do osso. Os triângulos em azul são a condição de simetria do modelo.

Em verde, estão representados os pontos dos elementos que sofrerão o deslocamento na ativação do aparelho, ou seja, se encaixam nos fios imediatamente acima deles.

\section{Conclusões}

O modelo computacional gerado foi considerado satisfatório ao ser avaliado pelo dentista responsável pelo caso. Espera-se enviar os resultados da simulação, com a finalização futura do projeto, para avaliação pelo ortodontista. É importante citar a importância da multidisciplinaridade necessária para a realização deste trabalho, com a aplicação de fundamentos da engenharia e principalmente da anatomia e ortodontia em conjunto.

\footnotetext{
DA SILVA CARDOSO, Guilherme Alves; BARONE, Triuze Yano. Verticalização de Molares Inferiores. Revista da AcBO-ISSN 2316-7262, v. 1, n. 2, 2013.

JANSON, Marcos dos Reis Pereira; JANSON, Reinaldo dos Reis Pereira; FERREIRA, Paulo Martins. Tratamento interdisciplinar I: consideraçöes clínicas e biológicas na verticalizaçäo de molares. Rev. dent. press ortodon. ortop. maxilar, v. 6, n. 3, p. 87-104, 2001.

LOTTI, Raquel S. et al. Aplicabilidade científica do método dos elementos finitos. R Dental Press Ortodon Ortop Facial, v. 11, n. 2, p. 35-43, 2006.
} 